e-makâlât Mezhep Araştırmaları, VII/2 (Güz 2014), ss. 175-179.

ISSN 1309-5803 | www.emakalat.com

\title{
TWELVER SHIISM: UNITY AND DIVERSITY IN THE LIFE OF ISLAM, 632 TO 1722
}

Andrew J. Newman, Edinburgh University Press, Edinburgh, 2013, 272 s.

\section{Habip DEMİR*}

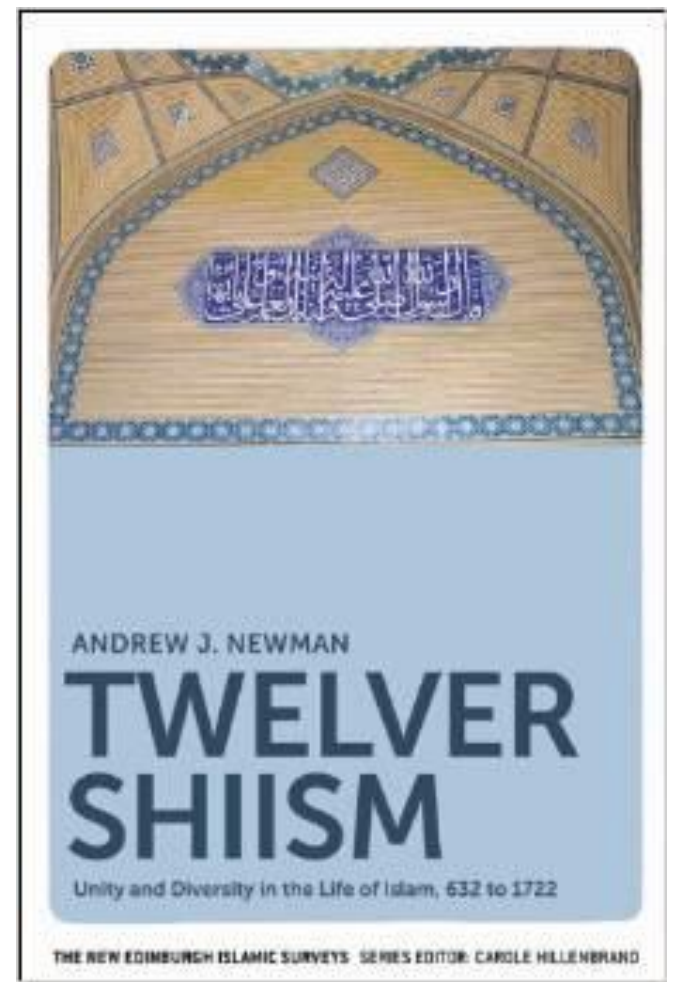

Bugün dünya Müslümanlarının yaklaşık yüzde 10'luk bir kısminı oluşturan İmâmiyye (İsnâaşeriyye/Caferilik) Şîa'sının tarihi ile ilgili çalışmaların özellikle 1979 İran Devrimi'nden sonra yoğun bir şekilde arttığını görmekteyiz. Özellikle $A B D$ ve İngiltere'de kurulmuş Orta Doğu Araştırmaları merkezleri, enstitüler ve düşünce kuruluşlarının en önemli ilgi alanlarından birisi, yüzyıllarca muhalefet hareketi olarak kalıp siyasi arenada boy göstermemeyi teolojik kökenlere bağlayan bir mezhebin nasıl olup da kitleleri harekete geçiren bir devrimin temel sürükleyici amili olduğunu ortaya koymak olmuştur. Bu bağlamda

*Arş. Gör. Iğdır Üniversitesi İlahiyat Fakültesi İslam Mezhepleri Tarihi Anabilim Dal, habibdemir06@gmail.com 
Şiîlik çalışmalarının nüfus ve temsil gücü dikkate alındığında daha çok İmâmiyye özelinde artma eğilimi sergilediğini söyleyebiliriz. ${ }^{1}$

Konu ile ilgili genellikle kısa dönemler üzerinde yoğunlaşmaya odaklı monografik çalışmaların aksine elimizdeki eser, Hz. Peygamber'in vefatından Safevî hanedanının yıkılış tarihi olan 1722 yılına kadarki dönemini şahıs, mekan, eser ve fikirler üzerinden ele almay1 amaçlayan İngiltere'de yayınlanmış son çalışmalardan birisidir. Eserin yazarı Prof. Dr. Andrew J. Newman ${ }^{2}$ halen Edinburgh Üniversitesi İslam ve Ortadoğu Çalışmaları Bölümü öğretim üyesi olarak görev yapmakta olup Batı'da Şiîlik araştırmaları denilince ilk akla gelen isimlerdendir. Elimizdeki eser yazarın bu alanda hazırladığı son kitabıdır.

Bir akademik disiplin olarak Batı'da Şîa çalışmalarının tahlili ile işe başlayan Newman, bu çalışmaların temel olarak Klasikçiler (Classicists) ve Modernistler'in çalışmaları şeklinde ikiye ayrılabileceğini belirtmektedir (s.2-8). W. Madelung, J. Eliash, E. Kohlberg, M. J. McDermott gibi Klasikçiler Şîa'nın daha çok doktrinel anlamda Arapça ana kaynaklar üzerinden tahlilini yapmışlar ardından bu grupla beraber sayabileceğimiz S. H. Nasr ve H. Corbin gibi felsefe kökenli araştırmacılar Şîa'yı ezoterik bir inanç olarak Tasavvufla olan bağlantıları noktasında karşılaştırmalı olarak incelemişlerdir (s.3). Şiîlik üzerine yoğunlaşan araştırmacılar, 1501'de Safevî hane-

${ }^{1}$ Batı'da Şiilik çalışmaları ile ilgili bibliyografya için bkz. Mehmet Toprak, "Batıda İmâmiyye Şîası İle İlgili Çalışmalar", Oryantalizmi Yeniden Okumak Batı'da İslam Çalışmalar Sempozyumu, DİB Yay., Ankara, 2003; Mehmet Ali Büyükkara, "Batıda İmâmiyye Şîası İle İlgili Çalışmalar", Başlıklı Tebliğin Müzakeresi, Oryantalizmi Yeniden Okumak Batı'da İslam Çalışmalar Sempozyumu, DİB Yay., Ankara, 2003, s. 467; Habib Kartaloğlu, "Batıda Şia İle İlgili Yapılan Çalışmalar: Bibliyografik Bir Deneme”, e-makâlât Mezhep Araştirmalar, V/ 1 (Bahar 2012), ss. 119-140.

2 Newman'ın başlıca çalışmaları: The Development and Political Significance of the Rationalist (Usulî) and Traditionalist (Ahbârî) Schools in Imami Shii History: From the Third/Ninth to the Tenth/Sixteenth Century A.D (1986, California Üniversitesi, Doktora tezi), The Formative Period of Twelver Shi-'ism: Hadith as Discourse between Qum and Baghdad (2000), Safavid Iran: Rebirth of a Persian Empire (2006), Society and Culture in the Early Modern Middle East: Studies on Iran in the Safavid Period (2003 ed.) 
danının kurulmasını müteakip Şîa'nın resmi mezhep oluşundan hareketle bu dönemi kırılma noktası olarak belirlemiş ve çalışmalarını daha çok İran merkezli ve dönemin sosyo-politik arka planını ortaya çıkarma üzerine yoğunlaştırmışlardır (s.3). Bu bağlamda 1979 devriminin Şîa çalışmaları için hem metodik hem de zihinsel bir dönüşüme neden olduğunu düşünen yazar, bu dönemden sonra artık Şîa'yı sadece ezoterik ya da belirli bir alana sıkıştırılmış konulardan ziyade siyasi, toplumsal, ekonomik arka planı ile birlikte inceleme ihtiyacı doğmuştur. Ayrıca İran dışındaki Şiîlerin de varlığı bir anlamda keşfedilmiş Irak, Lübnan, S. Arabistan başta olmak üzere dünyanın değişik bölgelerinde yaşayan Şiîlerin durumu da dikkate alınır olmuştur. Şîa tarihini 1501 öncesi ve sonrası olarak ikiye ayırmanın yeterli olmayacağını belirten yazar, Şî’nın 1722 yılındaki Safevî hanedanının yıkılışına kadar olan süreyi ayrılmaz bir bütün olarak görmenin daha isabetli olacağını düşünmüştür.

Çalışmasını 9 bölüme ayıran yazar her bir bölümü kendi döneminin orijinal kaynaklarına inerek incelemeye çalışmış ardından modern literatürün dönemle ilgili geldiği noktayı özetlemiştir. Metod olarak her bölümün sonuna bir özet ve değerlendirme eklemesi okuyucu açısından bir kolaylık sağlamıştır.

Eserin bölümleri ve İçerikleri hakkında kısa bilgiler;

Birinci Bölüm'de Hz. Peygamber'in vefatının ardından yaşanan gelissmeler ve bunların İslam toplumundaki ayrışmalara olan etkisinden bahsedildikten sonra İmamiyye Şîa'sının imam olarak kabul ettiği şahıslar hakkında özet bilgiler verilmektedir. Bölümün sonunda haklı olarak yazar, bu döneme ait kaynakların önemli bir bölümünün güvenirlik açısından sorunlu olduğunu vurgulamaktadır. Bu bölümde Taberî, Yakubî, Mesudî dışında ana kaynak kullanmamış daha çok İngilizce modern kaynaklardan istifade etmiştir.

Íkinci Bölüm; yaklaş1k olarak m. 870'de son imamın ortadan kaybolmasından Büveyhîlerin iktidara geldiği 940 yılına kadarki dönemi kapsamaktadır. 12. İmamın gaybete çekilmesinin ardından Şiî toplumunun ayakta kalabilmek için giriştiği çabalar ile Kum ve Bağdat ulemasının hadis birikimi ve bunların yansıması olarak önemli hadis mecmuaları hakkında bilgiler vermektedir. Bu Bölüm- 
de yazar konu ile ilgili 2000 yılında yayınlamış olduğu The Formative Period of Twelver Shi-'ism: Hadith as Discourse between Qum and Baghdad adlı eserine siklıkla atıfta bulunmuştur.

Üçüncü Bölüm; Şiîliğin itikadi yapılanmasının tamamlandığı gaybet döneminin önemli müellifleri ve onların günümüze kadar etkisi devam eden eserleri hakkında bilgilerin verildiği bölümdür. Bu bölümde Ali b. Bâbeveyh (ö. 329/940)'in Kitâbu'l-İmâme ve't-Tabsira mine'l-Hayra, İbn Ebî Zeyneb Nu'mânî (ö. 360/971)'nin Kitâbu'lGaybe, İbn Kavleveyh (ö.368/978)'in teoriyi pratiğe dönüştüren Kâmilu'z-Ziyârât'ı ele alındıktan sonra dönemin en seçkin ismi İbn Bâbeveyh el-Kummî (Şeyh Sadûk)'ye (ö.381/991) özel bir yer açmaktadir. Onun Kemâlu'd-Dîn Tamâmu'n-Ni'me, Uyûnu Ahbâri'rRizâ, el-i'tikâdât ve son olarak el-Fâkîh (Men Lâ Yahduruhu'l-Fakîh) adlı eserleri incelenmektedir.

Dördüncü Bölüm; Bu bölümde Şiî fikhının rasyonelleşme sürecinde Şeyh Müfid, Şerif el-Murtaza, Şeyh Tûsî özelinde Bağdat Şiiliği üzerine yoğunlaşılmaktadır.

Beşinci Bölüm; Selçukluların Bağdat'a girişi sonrasında Şiîliğin ayakta kalma mücadelesi anlatılmaktadır. Bu bağlamda Şiîliğin Suriye ve İran'daki temsilcileri hakkında bilgi verdikten sonra mezhebin fikri merkezinin Bağdat'tan Hille'ye kayışı ve sonrasındaki gelişmelerden bahsedilmektedir.

Altıncı Bölüm; Moğol istilası sonrasında Bağdat ekolünün yerini Hille ekolünün almasını ve bu ekolün önemli temsilcilerini incelemektedir.

Yedinci Bölüm; Allame H1llînnin 726/1325’teki ölümünden Safevîlerin kuruluşu olan 1501 tarihine kadarki dönemi ele almaktadır. $\mathrm{Bu}$ dönemde Şîa'nın çeşitli zorluklarla karşılaştığı ve belirgin bir ilmi merkezinin olmayışının ne tür sorunlara yol açtığı anlatılmaktadır. Bu bölümde İbn Mekkî'nin çalışmaları, Hicaz'daki Şiîlerin durumu, Timurlular dönemi ve tasavvufla yakınlaşma aşamaları el alınmaktadır.

Sekizinci Bölüm; 1501 yllında Safevîlerin kuruluşu ile birlikte Şiî dünyada meydana gelen değişimler ele alınmaktadır. Bu bölümde 
Şiîliğin İran, Irak, Lübnan, Körfez bölgesi ile Hindistan'daki temsilcileri hakkında kısa bilgiler sunulmaktadır.

Dokuzuncu ve son bölümde ise XVII. yüzyılda bir bütün olarak Şiî dünyası ele alınmaktadır. Burada Safevî hanedanının son dönemindeki Şiî temsilciler, Lübnan, Irak, Körfez bölgesi ve Hint alt kıtas1 ele alınmaktadır.

Eserin eklerinde ele alınan dönemde şehirlere göre müelliflerin sayıs1, eserlerin hangi yüzyıllara ait olduğu ile ilgili kronolojik tablo, Safevîler dönemindeki rical literatürü ile birlikte geniş bir bibliyografya verilmektedir.

Eser Şîilik araştırmacıları için gerek kaynak gerekse metod açısından herhangi bir yenilik getirmiş olmamasına rağmen uzun say1labilecek bir dönemle ilgili sistematik ve derli toplu bilgiler vermiş olması, Arapça, Farsça ve İngilizce literatürün tamamının kullanılması açısından bir el kitabı olarak düşünülebilir. Bu özelliğiyle Türkçe'ye kazandırılmasının İslam Mezhepleri Tarihi Anabilim Dalı açısından bir gereklilik olduğunu düşünüyorum. 
